\title{
Pengaruh Proses Refining Minyak Bekas Sebagai Bahan Baku Biodiesel
}

\author{
Ni Made Suaniti ${ }^{1)^{*}}$, I Wayan Bandem Adnyana ${ }^{2)}$ \\ ${ }^{1)}$ Program Studi Kimia, Fakultas MIPA, Universitas Udayana, Kampus Bukit Jimbaran Bali \\ ${ }^{2)}$ Program Studi Mesin, Fakultas Teknik, Universitas Udayana, Kampus Bukit Jimbaran Bali \\ naskah masuk 15/07/2018; diterima 20/10/2018; terbit 29/10/2018 \\ doi: 10.24843/JEM.2018.v11.i02.p08
}

\begin{abstract}
Abstrak
Penampakan minyak bekas hasil penggorengan yang berwarna cokelat gelap tidak baik dikonsumsi akibat sifat fisik dan kimia minyak berubah sehingga dapat dimanfaatkan sebagai bahan bakar atau biodiesel. Tujuan penelitian ini adalah menganalisis bahan baku minyak hasil penggorengan setelah direfining dengan asam sulfat dan biodiesel hasil proses transesterifikasi dengan $\mathrm{CaO}$ sebagai katalis heterogen. Metode yang digunakan adalah spektroskopi Infra merah dan pengukuran secara mikroskopik. Hasil refining minyak bekas dengan asam sulfat lebih jernih dan analisis secara Infra Merah menunjukkan bahwa terjadi penurunan serapan pada berbagai bilangan gelombang dibandingkan terhadap minyak bekas. Serapan terjadi pada bilangan gelombang $2900 \mathrm{~cm}^{-1}$ diduga adanya ikatan $\mathrm{CH}_{3},-\mathrm{CH}_{2}-,-\mathrm{C}-\mathrm{H} ; 1656 \mathrm{~cm}^{1}$ diduga adalah ikatan $\mathrm{C}=\mathrm{C}$ dan $\mathrm{C}=\mathrm{O} ; 1300 \mathrm{~cm}^{-1}$ diduga ikatan-C- $\mathrm{H}$; dan $3600 \mathrm{~cm}^{-1}$ diduga adanya ikatan $\mathrm{O}-\mathrm{H}$. Secara mikroskopik menunjukkan hasil dengan ukuran partikel semakin kecil dan lebih homogen.
\end{abstract}

Kata kunci: biodiesel, minyak bekas, refining, infra merah, mikroskopik

\section{Abstract}

The appearance of dark brown frying oil that is used for frying is not well consumed due to the changing physical and chemical properties of the oil so that it can be used as fuel or biodiesel. The aim of this study was to analyze the raw material of frying oil after being refined with sulfuric acid and biodiesel from the transesterification process with $\mathrm{CaO}$ as a heterogeneous catalyst. The method used is infrared spectroscopy and microscopic measurements. The results of refining used oil with sulfuric acid became clear and infrared analysis showed that there was a decrease in absorption at various wave numbers compared to used oil. Absorption occurred at wave numbers 2900 $\mathrm{cm}^{-1}$ was suspected to have $-\mathrm{CH}_{3},-\mathrm{CH}_{2^{-}}, \mathrm{C}-\mathrm{H}$ bonds; $1656 \mathrm{~cm}^{-1}$ was thought to be $\mathrm{C}=\mathrm{C}$ and $\mathrm{C}=\mathrm{O}$ bonds; $1300 \mathrm{~cm}^{-1}$ was -C-H bond; and $3600 \mathrm{~cm}^{-1}$ was suspected to be $\mathrm{O}-\mathrm{H}$ bond. Microscopically shows the results with smaller and more homogeneous particle sizes.

Keywords: biodiesel, infrared, microscopic, used oil, refining

\section{Pendahuluan}

Penelitian tentang pembuatan biodiesel berbahan dasar minyak bekas penggorengan telah sering dipublikasikan, namun usaha dan upaya perbaikan terus dikembangkan untuk memperoleh karakteristik sesuai persyaratan untuk mesin diesel.

Minyak jelantah hasil penggorengan beberapa kali dapat membuat cita rasa gorengan menjadi kurang enak, kemungkinan terbentuk senyawa baru karena serangkaian reaksi seperti oksidasi, reduksi, hidrolisis. Lemak dengan kandungan asam lemak tak jenuhnya tinggi, berwujud cair pada suhu ruangan dikenal sebagai minyak sedangkan kandungan asam lemak jenuh berwujud padat (Edward dkk., 2001). Minyak jelantah hasil dekomposisi asam lemak yang tidak layak dikonsumsi dapat dimanfaatkan sebagai bahan bakar. Kandungan lemak dalam minyak ini akan mempengaruhi jenis dan jumlah asam lemak yang diperoleh sehingga diperlukan refining secara kimia sebelum dilakukan proses transesterifikasi dalam pembuatan biodiesel.

Asam sulfat sebagai salah satu material anorganik telah digunakan sebagai katalis dalam pembuatan biodiesel (Yuliana et al., 2003: Suirta, 2009; Fitriyana et al., 2012), menurut Yuliana bahwa asam sulfat 0,5\% dengan waktu reaksi 120 menit pada suhu $60^{\circ} \mathrm{C}$ mampu menurunkan free fatty acid (FFA) kurang dari $2 \%$. Asam sulfat dapat secara simultan digunakan baik dalam proses esterifikasi dan transesterifikasi untuk memperoleh hasil yang lebih tinggi dalam bentuk ester. Biodiesel sebagai suatu fuel alternative yang ramah lingkungan dan sumber energy terbarukan melalui empat metode yaitu: blending, pyrolysis, mikroemulsi, dan transesterifikasi (Agarwal, et al., 2015). Sebagai upaya perbaikan karakterisasi asam sulfat digunakan dalam proses refining minyak bekas selanjutnya dilakukan transesterifikasi dengan etanol untuk memperoleh biodiesel menggunakan katalis heterogen yaitu $\mathrm{CaO}$.

\section{Metode Penelitian}

\subsection{Bahan-Bahan Penelitian}

Minyak bekas penggorengan, $\mathrm{H}_{2} \mathrm{SO}_{4}$ p.a, $\mathrm{H}_{3} \mathrm{PO}_{4}$ p.a, $\mathrm{CaO}$, etanol p.a. $99 \%, \mathrm{CaCl}_{2}$ anhidrat, akuades, Instrumen FTIR Shimadzu Pretige 21, seperangkat alat refluks, alat-alat gelas, kertas saring Whatman 
(Glass microfiber Filters GF/C Circles 110mm, Cat No 1822 110, dan mikroskop Nikon Eclipse Ni.

\subsection{Prosedur Penelitian}

Metode yang digunakan dengan cara minyak bekas dipanaskan selama 5 menit lalu direndam dalam $\mathrm{H}_{2} \mathrm{SO}_{4}$ selama 24 jam kemudian disaring. Minyak hasil saringan sebanyak $100 \mathrm{~mL}$ dimasukkan dalam corong leher dua, ke dalamnya ditambahkan $20 \mathrm{~mL}$ etanol dan $0,5 \mathrm{~mL} \mathrm{CaO}$ teraktifasi asam fosfat. Selanjutnya larutan dipanaskan selama 2,5 jam pada suhu $55^{\circ} \mathrm{C}$ sementara didinginkan kemudian dimasukkan ke dalam corong pisah dan ditambahkan $100 \mathrm{~mL}$ akuades hangat. Setelah terpisah lapisan atas ditampung dalam beker gelas dan ditambahkan $\mathrm{CaCl}_{2}$ sampai diperoleh larutan yang hampir jernih lalu disaring dan diperoleh biodiesel. Untuk mengetahui terjadi perubahan sifat fisik dan kimia antara minyak bekas, minyak bekas hasil refining, dan Biodiesel dianalisis secara FTIR dan mikroskop.

Radiasi infra merah (IR) sebagai spektrum elektromagnetik yang dapat diukur pada daerah sinar tampak dan gelombang mikro antara $4000-400 \mathrm{~cm}^{-1}$. Namun dalam penggunaannya umumnya digunakan istilah bilangan gelombang yaitu kebalikan dari panjang gelombang sebagai jumlah gelombang per $\mathrm{cm}$ sesuai rumus $2-1$ berikut:

$$
\begin{aligned}
& 1 \times 10^{-4} \\
& \text { bilangan gelombang, } \bar{v} \quad\left(\mathrm{~cm}^{-1}\right)=\frac{}{\text { panj. gel dlm } \mu \mathrm{m}} \\
& \bar{v}=4000-.666 \mathrm{~cm}^{-1} \\
& \lambda=2,5-15 \mu \mathrm{m}
\end{aligned}
$$

Interpretasi IR, sebagai pendeteksian awal bahwa biodiesel dapat terbentuk. Proses transesterifikasi minyak bekas yang telah direfining, menggunakan katalis $\mathrm{CaO}$ dapat membentuk Fatty acid ethyl esters (FAEEs) (Yuan et al., 2014). Dugaan kandungan ethyl ester secara IR dalam biodiesel secara ringkas

\begin{tabular}{|c|c|c|}
\hline No. & $\bar{v}\left(\mathrm{~cm}^{-1}\right)$ & $\begin{array}{l}\text { Dugaan Ikatan } \\
\text { mengabsorpsi }\end{array}$ \\
\hline 1 & $3750-3000$ & $\mathrm{O}-\mathrm{H}, \mathrm{N}-\mathrm{H}$ \\
\hline 2 & $3300-2900$ & $\begin{array}{l}\mathrm{C}-\mathrm{H} \\
\text { dari }-\mathrm{C} \equiv \mathrm{C}-\mathrm{H}-\mathrm{H} ; \mathrm{C}=\mathrm{C}-\mathrm{H} \text {; }\end{array}$ \\
\hline 3 & $3000-2700$ & $-\mathrm{CH}_{3} ;-\mathrm{CH}_{2}-;-\mathrm{C}-\mathrm{H}$ \\
\hline 4 & $2400-2100$ & $\mathrm{C}=\mathrm{C} ; \mathrm{C}=\mathrm{N}$ \\
\hline 5 & $1900-1650$ & $\begin{array}{l}\mathrm{C}=\mathrm{O} \text { (Asam, aldehida, keton, } \\
\text { amida, ester, anhidrida }\end{array}$ \\
\hline 6 & $1675-1500$ & $\mathrm{C}=\mathrm{C}$ (alifatik, aromatik); $\mathrm{C}=\mathrm{N}$ \\
\hline 7 & $1475-1300$ & $-\mathrm{C}-\mathrm{H}-$ \\
\hline 8 & $1000-650$ & $\mathrm{C}=\mathrm{C}-\mathrm{H} ; \mathrm{Ar}-\mathrm{H}$ \\
\hline
\end{tabular}
dirangkum sesuai Tabel 1.

Tabel 1 Bilangan gelombang IR dengan kemungkinan gugus fungsi terlibat

\subsection{Massa jenis Biodiesel}

Massa jenis sebagai perbandingan massa persatuan volume, berkaitan dengan nilai kalor dan daya yang dihasilkan oleh mesin diesel persatuan volume bahan bakar. Kerapatan suatu fluida dapat didefinisikan sebagai massa per satuan volume, yaitu :

$$
\begin{gathered}
\rho=\mathrm{m} / \mathrm{v} \ldots \ldots \ldots \ldots \ldots \ldots \\
\text { Dengan, } \rho=\operatorname{rapat} \text { massa }\left(\mathrm{g} / \mathrm{cm}^{3}\right) \\
\mathrm{m}=\text { massa }(\mathrm{g}) \\
\mathrm{v}=\operatorname{volume}\left(\mathrm{cm}^{3}\right)
\end{gathered}
$$

\section{Hasil dan Pembahasan}

\subsection{Randemen Biodiesel}

Proses pemanasan minyak secara berulang dapat mengubah struktur dan sifat fisik dan kimia minyak. Hasil penelitian menunjukkan bahwa terjadi perubahan warna dari coklat menjadi jernih dari minyak bekas, minyak hasil refining, dan biodiesel. Randemen biodiesel $80 \%$ dengan berat jenis $0,854 \mathrm{~g} / \mathrm{cm}^{3}$ susuai Standar Nasional Indonesia yaitu SNI:04-7182-2006. Biodiesel yang diperoleh dari minyak bekas penggorengan ikan sangat tergantung pada proses esterifikasi dan transesterifikasi menggunakan katalis asam-basa, kromatografi lapis tipis sebagai salah satu teknik yang sederhana untuk memonitor transesterifikasi (Fadhil et al., 2012).

Hasil spektra IR juga terlihat perubahan serapan pada bilangan gelombang spesifik seperti diperlihatkan dalam Gambar 1. Hasil mikroskopik diperlihatkan dalam Gambar 2. Ukuran partikel minyak bekas bervariasi dari 5,64 - 10,26 $\mu \mathrm{m}$, minyak bekas hasil refining sekitar $4 \mu \mathrm{m}$, dan biodiesel mempunyai ukuran lebih dari $5 \mu \mathrm{m}$.

Proses pemanasan minyak dalam suhu tinggi akan menyebabkan minyak mengalami pirolisis yaitu reaksi dekomposisi karena panas, terbentuk senyawa akrolein yaitu senyawa sejenis aldehid tak jenuh yang bersifat racun dan dapat menyebabkan iritasi tenggorokan dengan khas bau lemak terbakar (Edwar dkk, 2011).

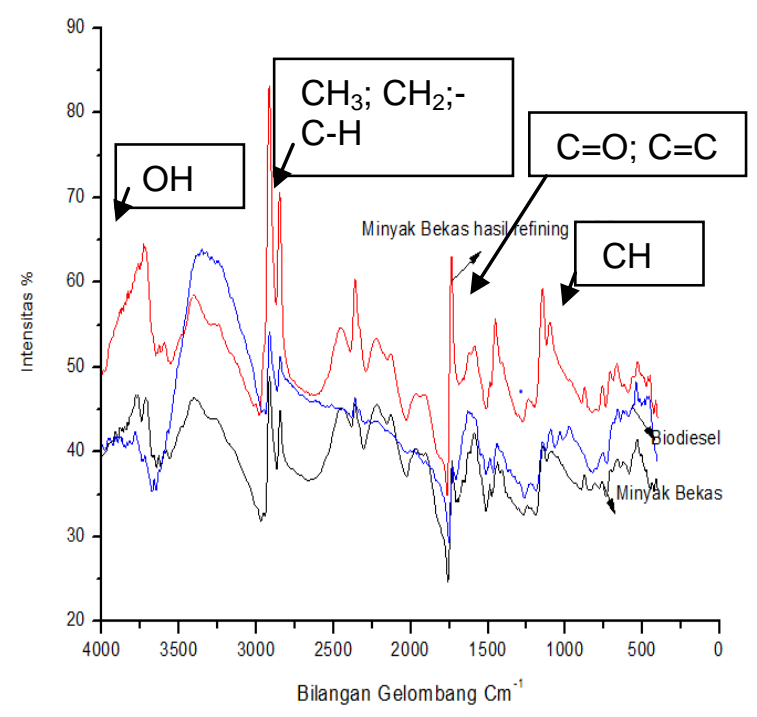

Gambar 1 Perbandingan spektra IR dalam minyak bekas, minyak bekas hasil refining, dan biodiesel minyak bekas hasil refining menggunakan katalis $\mathrm{CaO}$ 


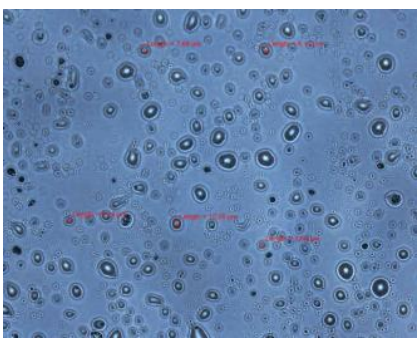

a) Minyak bekas

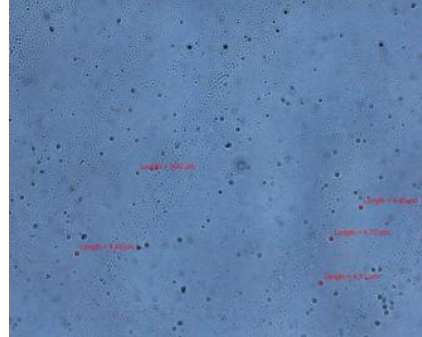

b) Minyak bekas hasil refining

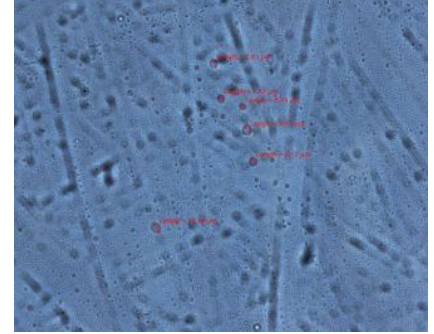

c) Biodiesel

Gambar 2. Hasil Minyak bekas, hasil refining, dan biodiesel secara mikroskopik

Akrolein dan bahan berbahaya lainnya dapat terbentuk dalam bahan yang digoreng, akibat hidrasi gliserol dengan air, atau penambahan plastik dalam minyak sehingga minyak menjadi jernih dan kerenyahan gorengan bertahan lama.

Hasil FTIR pada Gambar 1 terdeteksi gugus fungsi Serapan pada bilangan gelombang $2900 \mathrm{~cm}^{-1}$ diduga adanya ikatan $-\mathrm{CH}_{3} ;-\mathrm{CH}_{2-}$, dan $-\mathrm{C}-\mathrm{H} ; 1650 \mathrm{~cm}^{1}$ diduga adalah ikatan $\mathrm{C}=\mathrm{C}$ dan $\mathrm{C}=\mathrm{O} ; 1300 \mathrm{~cm}^{-1}$ diduga ikatan-C-H lemah serta $3600 \mathrm{~cm}^{-1}$ diduga adanya ikatan $\mathrm{O}-\mathrm{H}$. Hasil ini didukung oleh penelitian Yuan et al., 2014, pada bilangan gelombang berturut-turut 1363, 1377, dan $1436 \mathrm{~cm}^{-1}$ dikatakan bahwa FAMEs yang diperoleh meningkat namun dengan ikatan lemah. Gugus $\mathrm{C}=\mathrm{O}$ sebagai penanda $\mathrm{FAME}$ dalam biodiesel terbentuk muncul pada daerah 1800-1700 $\mathrm{cm}^{-1}$ dan 1500-900 $\mathrm{cm}^{-1}$ dikenal sebagai daerah fingerprint, adanya $-\mathrm{CH}_{2}$ stretching asimetris dalam biodiesel dari minyak soybean (Rabelo, et al., 2015). Menurut Thermo Scientific (Application 51258), puncak ester kuat (vibrasi $\mathrm{C}=\mathrm{O}$ ) pada bilangan gelombang $1750 \mathrm{~cm}^{-1}$ dan vibrasi C-O sekitar $1170-1200 \mathrm{~cm}^{-1}$ (Bradley, tt), hampir sama Shimadzu (1875) $\mathrm{C}=\mathrm{O}$ ester sekitar 1743,65 $\mathrm{cm}^{-1}$ dalam biodiesel Edible Rape oil.

\section{Simpulan}

Proses refining minyak bekas dengan asam sulfat dapat memperbaiki sifat kimia dan lebih baik digunakan sebagai bahan baku biodiesel. Perubahan ikatan yang diduga secara infra merah adalah $\mathrm{C}-\mathrm{H}$, $\mathrm{C}=\mathrm{C}$, dan $\mathrm{O}-\mathrm{H}$. Secara mikroskopik menunjukkan bahwa minyak bekas hasil refining yang dibuat memiliki ukuran partikel semakin kecil dan lebih homogen.

\section{Ucapan Terima Kasih}

Terima kasih kepada Lembaga Penelitian dan Pengabdian Kepada Masyarakat dan Fakultas Matematika dan Ilmu Pengetahuan Alam dalam Kegiatan Penelitian Unggulan Udayana No. 2142/UN14.2.8.II/LT/2018, tanggal 26 Maret 2018.

\section{Daftar Pustaka}

[1] Fitriyana, L.A., Soeprodjo, Kadarwati, S., Indonesian Journal of Chemistry Science. 1, 2, Jurusan Kimia F.MIPA Universitas negeri Semarang. ISSN No. 2252-6951, 2012.

[3] Edward, D., Hudson, Robert, J., Helleur, Christopher, C., and Parrish, Thin Layer Chromatography-Pyrolysis-Gas ChromatographyMass Spectrometry: a Multidimensional Approach to marine Lipid Class and Molecular Species Analysis, Journal of Chromatographic Science, 39, April 2001

[4] Fontana, J.D., Zagonel, G., Vechiattoo, w.w., Costa, B.J., Laurindo, J.C., Fontana, R., Pelisson, L., Jorge, B.H., and Llancas, F.M., 2009, Journal of Chromatographic Science, 47, Oktober 2009

[5] Suaniti, NM. Perbedaan Kadar Etanol dalam Arak Enau dan Arak Kelapa Hasil Industri Rumah Tangga yang diproduksi di Bali dengan Kromatografi Gas. Prosiding Seminar Nasional Kimia. Surabaya, 28 Juli 2009. Jurusan Kimia F.MIPA ITS

[6] Suirta, IW. Preparasi Biodiesel dari Minyak Jelantah Kelapa Sawit. Jurnal jurusan Kimia F.MIPA Unud, 3, 1, 1-6. Bukit Jimbaran. Badung. Bali. ISSN 1907-9850, 2009.

[7] Yuliani, F., Primasari, M., Rachmaniah, O., Rachimoellah, M., Pengaruh katalis asam $\left(\mathrm{H}_{2} \mathrm{SO}_{4}\right)$ dan suhu reaksi pada reaksi Esterifikasi Minyak Biji karet (Hevea brasiliensis) menjadi Biodiesel. Laboratorium biomassa dan energi ITS Surabaya, 2003.

[8] Zakir, M., raya, I., Asbia, Optimalisasi Proses Sintesis dan Karakterisasi Biodiesel dari Minyak Algae Merah (Eucheuma cottonii) dengan katalis $\mathrm{KOH}$. Jurusan Kimia F.MIPA UnHas, 2010.

[9] Yuan, T., Akochi-Koble, E., Pinchuk, D., and Van de oort, F.R., FTIR on-line Monitoring of Biodiesel Transesterification. International journal of Renewable Energy \& Biofuels, DOI: 10.5171/ 2014.178474, 2014.

[10] Fadhil, A.B., Dheyab M.M., Ahmed K.M., and Yahya M.H., Biodiesel production from Spent Fish Frying Oil through Acid-Base Catalyzed Transesterification, Pak. J. Anal. Environ. Chem., 2012. 13 (1): 09-15, 2012

[11] Rabelo, S.N., Ferraz, V.P., Oliveira, L.S., and Franca, A.S., FTIR Analysis for Quantification of Fatty Acid Methyl Esters in Biodiesel Produces by Microwave-Assisted Transesterification, International Journal of Environmental Science and Development, 6 (12): 964-969, 2015. 
[12] Agarwal, A., Gupta, P., Raideep, biodiesel Production for Engine from Various Non-Edible Oils: A Review, international Journal of Emerging Engineering Research and Technology, 3 (1): 816,2015

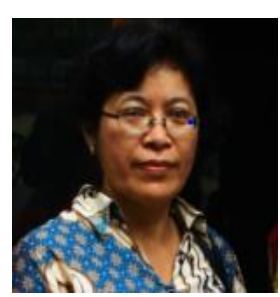

Ni Made Suaniti menyelesaikan pendidikan S1 MIPA-Kimia di Universitas Universitas Airlangga pada tahun 1990. Pendidikan magister Kimia diselesaikan di Universitas Padjadjaran pada tahun 1999 dengan area riset tentang Analisis Kimia secara Gas Chromatography-Mass Spektrometry.

Pada tahun 2010 ia menyelesaikan pendidikan doktoral di Universitas Udayana. Saat ini ia bekerja sebagai dosen di Program Studi Kimia, FMIPA Universitas Udayana. Bidang penelitian utama yang digeluti Analisis Fatty Acid Ethyl Ester dalam produk hasil sintesis dan Terapan

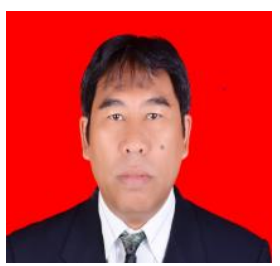

I Wayan Bandem Adnyana menyelesaikan studi program sarjana $d$ Jurusan Teknik Mesin ITS tahun 1990. Pendidikan magister Ergonomi Kerja diselesaikan di Universitas Udayana pada tahun 2001 dengan area riset Bahan Bakar dan Pengering . 